\title{
Characterization of cyclic nucleotide phosphodiesterase isoenzymes in the human ureter and their functional role in vitro
}

\author{
A. Taher ${ }^{1}$, P. Schulz-Knappe' ${ }^{2}$ M. Meyer ${ }^{1,2}$, M. Truss ${ }^{1,2}$, W.-G. Forssmann ${ }^{2}$, C. G. Stief ${ }^{1}$, and U. Jonas ${ }^{1}$ \\ ' Department of Urology, Medical School, Hannover, Germany \\ ${ }^{2}$ Lower Saxony Institute for Peptide Research, Medical School, Hannover, Germany
}

Summary. An increase in cyclic nucleotide monophosphate levels is suggested to play a prominent role in mediating smooth-muscle relaxation. Cyclic nucleotide phosphodiesterase (PDE) influences smooth-muscle tone by decreasing the level of cyclic nucleotides. At present, five different families of isoenzymes of PDE exist that show a distinct species- and organ-specific distribution. Our study was done to evaluate the existence of specific PDE isoenzymes and its functional role in human ureteral tissue. Normal ureteral tissue was homogenized and centrifuged and the supernatant fraction was separated using anioin-exchange diethylaminoethyl (DEAE)-Sephacel chromatography. A PDE assay was then performed and the peak fractions were added to different specific PDE activators and inhibitors. In vitro, longitudinal ureteral strips were precontracted and different selective and nonselective PDE inhibitors were added incremently. Three different PDE isoenzymes were characterized: PDE I (calmodulin-sensitive), PDE II (cGMP-stimulated), and PDE IV (cAMP-specific). All PDE inhibitors relaxed the strips dose-dependently, with the $50 \%$ effective concentrations $\left(\mathrm{EC}_{50}\right.$ ) being $30 \mu M$ for papaverine, $40 \mu M$ for zaprinast, $25 \mu M$ for quazinone, and $0.1 \mu M$ for rolipram. The ureter-relaxing effect of the PDE IV inhibitor at low concentrations, combined with its low-level effect on the systemic circulatory parameters, may open the possibility of using selective PDE IV- inhibitors in the treatment of ureteral colics or for ureteral stone passage.

The incidence of urinary-tract stone disease in Germany is estimated to be $0.1 \%$, with the prevalence for primary stones being $4 \%-5 \%$. In the case of an uncomplicated renal or ureteral stone, the application of intravenous analgesics is the most useful means of relieving the pain [1, $2]$. With respect to the potential beneficial effect of ureteral relaxation on stone passage, some spasmolytic agents such as phentolamine and orciprenaline have been shown to dilate the ureteral lumen at the level of an artifi-

Correspondence to: Dr. C. Stief, Department of Urology, MHH, D-30623 Hannover, Germany, Fax: 49(511)5323481 cial concretion and, thus, to allow increased fluid flow beyond the concretion.

Many drugs have been used in ureteral colic management [3], but the drug that can relief pain and facilitate stone passage with minimal systemic side effects is missing. One family of drugs used in the treatment of ureteral colics is the prostaglandin synthetase inhibitor [4]. These drugs not only relieve the pain but also facilitate stone passage [5]. The most effective mode of administration is the intravenous route, but in 55\% of cases, side effects occur. However, since these drugs also decrease the renal blood flow, they may induce renal failure, especially in obstructed kidneys $[4,5]$.

In recent years there has been increasing evidence that cyclic nucleotides [cyclic adenosine monophosphate (cAMP) and cyclic guanidine monophosphate (cGMP)] play an important role in the regulation of smooth-muscle tone [6]. cAMP increases the rate of $\mathrm{Ca}^{2+}$ uptake into the storage site (sarcoplasmic reticulum) and causes a decrease in the intrasarcoplasmic $\mathrm{Ca}^{2+}$ concentration, leading to smooth-muscle relaxation [7]. The degragation of cyclic nucleotides is catalyzed not by a single enzyme but by a number of different isoenzymes of phosphodiesterase (PDE). Recent data suggest that five different isoenzymes exist and that these show distinct species and tissue differences [8]. Since specific inhibitors of the isoenzyme families have been described, selective inhibition of a specific PDE isoenzyme may induce the same therapeutic effect with fewer side effects as compared with nonselective inhibition.

The aim of our study was to characterize PDE isoenzymes in the human ureter. Since the mere presence of an enzyme does not give any information on its functional significance, an in vitro study was done to examine the effect of selective PDE inhibitors on isolated ureteral smooth-muscle strips.

\section{Material and methods}

Ureters were taken from patients who had undergone radical nephrectomy for a malignant renal tumor. Preoperatively, radioisotope nephrograms were routinely done and showed a renal function 
of at least $100 \mathrm{ml} / \mathrm{min}$ in the renal units from which the ureters were taken. After excision, the ureter specimens were immediately placed in ice-cold saline, minced, and placed in 8 weight vols. of PDE isolation buffer $\left[10 \mathrm{~m} M\right.$ TRIS, $2 \mathrm{mM} \mathrm{MgCl}_{2}, 1 \mathrm{~m} M$ dithiothreitol (DTT); pH 7.5]. After ultraturrax homogenization, the homogenate was centrifuged at $40,000 \mathrm{~g}$ for $30 \mathrm{~min}$. The supernatant was used as a source of cytosolic PDE. The pellet was resuspended and again centrifuged to cover the remaining cytosolic PDE. The resultant pellet was used to determine the PDE activity of the particulate fraction.

Separation of PDE isoenzymes was performed using anion-exchange chromatography [diethylaminoethyl (DEAE)-Sephacel column, $16 \times 150 \mathrm{~mm}$ ]. Q-Sepharose (column, $10 \times 125 \mathrm{~mm}$ ) was used only in rechromatography. The columns were equilibrated with $10-15$ bed vols. of buffer A (70 $\mathrm{m} M$ sodium acetate, $1 \mathrm{~m} M$ DTT; $\mathrm{pH} 6.5)$. The filtered $(0.45 \mu \mathrm{m})$ supernatant $(4-6 \mathrm{ml})$ was applied using a $500-\mu \mathrm{I}$ injection loop, with multiple injections being delivered via a manual-injection valve. After a 2 -bed-vol. wash, the bound material was eluted from the column using a linear 70 - to $1,000-\mathrm{m} M$ sodium acetate gradient $(0-100 \%$ buffer $\mathrm{B}$ : $1,000 \mathrm{~m} M$ sodium acetate, $1 \mathrm{mM}$ DTT; pH 6.5) in 240 min at a flow rate of $1 \mathrm{ml} / \mathrm{min}$. UV absorption was detected at $254 \mathrm{~nm}$. Fractions $(3 \mathrm{ml})$ were collected and assayed for PDE activity.

A modification of the assay method of Thompson et al. [9] and Lakey et al. [10] was used. In brief, the PDE present in the tissue extract cleave the $3^{\prime}, 5^{\prime}$-phosphodiester bond of $3^{\prime}, 5^{\prime}$-cAMP. A mixture of tritiated cAMP and normal cAMP was used as a substrate in the reaction. $5^{\prime}$-AMP was then converted to adenosine by the addition of nucleotidase from snake venom (Crotalus atrox). Tritiated adenosine was then precipitated with the anion-exchange resin. The resultant radioactivity of adenosine in the supernatant was measured in a beta counter after the addition of scintillation cocktail. This method is equally applicable to measurement of the hydrolysis of cGMP. All assays were performed in duplicate. The results were expressed as the amounts (in picomoles) of cyclic nucleotide hydrolyzed per milliliter of enzyme preparation per minute. Blank values were determined by adding the elution buffer at various ionic strenghts and a linear increase in activity was found. For calculations, these blank values were subtracted.

\section{PDE isoenzyme characterization}

Except for measurements of enzyme kinetics, the substrate concentration used was $1 \mu M$ for cAMP and cGMP. The substrate specificity of all fractions was tested by incubating every second fraction with CAMP or CGMP, thus possibly allowing the identification of PDE IV or V. To examine the effect of calcium and calmodulin on cAMP/cGMP hydrolysis, calcium chloride $(10 \mu M)$ and bovine-heart calmodulin $40 \mathrm{n} M$ were added to the fractions. The presence of calmodulin-sensitive PDE (PDE I) was thus evaluated. To examine the effect of CGMP on cAMP hydrolysis, $5 \mu M$ cGMP was added to the assay tubes. The presence of cGMP-inhibited (PDE III) or cGMP-stimulated (PDE II) PDE was evaluated using this test.

\section{Effect of various PDE inhibitors}

Various PDE inhibitors were tested at concentrations ranging from $10^{-7}$ to $10^{-4} M$ to distinguish the inhibition of PDE hydrolytic activity in the peak fractions. Papaverine was used as the nonselective PDE inhibitor, and the selective PDE inhibitors were zaprinast (PDE I/V inhibitor), quazinone (PDE III inhibitor), and rolipram (PDE IV inhibitor). No selective inhibitor of PDE II is available. Dose-response curves were generated and $\mathrm{IC}_{50}$ values (concentrations producing $50 \%$ inhibition of substrate hydrolysis) were determined graphically.

\section{Enzyme kinetics}

Michaelis constants $K_{\mathrm{m}}$ values, i.e., the substrate concentration that produces $50 \%$ of the maximal reaction velocity) and $\mathrm{V}_{\max }$ (maxi- mal reaction velocity) values were determined using the Lineweaver-Burke plotting method [11]. The following substrate concentrations were used: $100,50,37.5,25,12.5,10,7.5,5,2,1.5$, $1,0.5$ and $0.1 \mu M$.

\section{In vitro study}

For the in vitro study, ureters were directly placed in $4^{\circ} \mathrm{C}$ solution [potassium chloride, $4.6 \mathrm{mM}$; sodium bicarbonate $15 \mathrm{~m} M$; sodium chloride, $119 \mathrm{mM}$; $\mathrm{NaH}_{2} \mathrm{PO}_{4}, 1.2 \mathrm{mM}$; magnesium chloride, 1.2 $\mathrm{m} M ; \mathrm{Na}_{2}$-Ca-ethylenediaminetetraacetic acid (EDTA), $0.1 \mathrm{~m} M$; and glucose, $20 \mathrm{~g}$. The solution was gassed with carbogen $(95 \%$ $\mathrm{O}_{2}, 5 \% \mathrm{CO}_{2}$ ) to adjust the $\mathrm{pH}$ to 7.4 before $1.5 \mathrm{mM} \mathrm{CaCl} 2$ was added. All experiments were performed within $24 \mathrm{~h}$ of tissue excision; previous control studies had shown that ureteral strips preserved in this manner gave results identical to those obtained with specimens taken immediately from the operating room. Ureteral strips of 8- to $10-\mathrm{mm}$ length and 3- to 4-mm width were mounted in a $10-\mathrm{ml}$ organ-bath chamber (transducer, Statham force displacement transducer; amplifier, Semmeg 9000 Burster Gernsbach PräzisionsmeBtechnik; polygraph, Linseis type 2025) and continuously gassed with carbogen at $37^{\circ} \mathrm{C}$.

The preparations were allowed to equilibrate for $60-90 \mathrm{~min}$, during which time the passive tension was set at $0.5 \mathrm{~g}$ by repeated adjustments. Then $80 \mathrm{mMKCl}$ was added to precontract the strips; after a stable degree of tension had been reached (plateau), the test substances were added. Several concentrations were tested on each strip until a relaxation of more than $50 \%$ was reached. In a pilot study, ureteral strips were contracted by different pharmacological agents (noradrenalin, prostaglandin 2-alpha carbachol, endotheline, $20 \mathrm{~m} M \mathrm{KCl}$ ), but none of them produced a stable contraction sufficient for relaxation studies.

Each PDE inhibitor was tested on three different ureteral preparations. Responses were expressed as the percentage of relaxation of $\mathrm{KCl}$-induced contractions. Cumulative concentrationresponse curves were generated for each substance, and the $\mathrm{EC}_{50}$ values (drug concentrations producing $50 \%$ relaxation) were determined graphically by linear interpolation.

\section{Statistical analysis}

The results are presented as mean values \pm SEM ( $n$ denotes the number of preparations examined). Student's two-tailed $t$-test was used for between-group comparisons of data. A probability level of $<0.05$ was accepted as significant. All statistical evaluations were calculated using the STAT VIEW 512 program (Brain Power Inc., USA).

\section{Results}

\section{PDE isoenzyme determination}

In all, $82 \%$ ot the total homogenate PDE activity was found in the supernatant fraction. The activity of the particulate fraction was $18 \%$. The ratio of cAMP to cGMP hydrolysis (at the $1-\mu M$ initial concentration) in the supernatant fraction was 1.1:1. In two experiments evaluated, $86.9 \%$ of the total activity applied to the anion exchange column was recovered after elution in different fractions Figure 1 shows the hydrolysis of either cAMP or cGMP initiated by the fractions eluted from the DEAE-Sephacel column. The effect of the addition of $5 \mu M$ cGMP to the fractions on cAMP hydrolysis is depicted in Fig. 2. As illustrated, three different peaks with hydrolytic activity were resolved from human ureter extracts by DEAESephacel chromatography. 


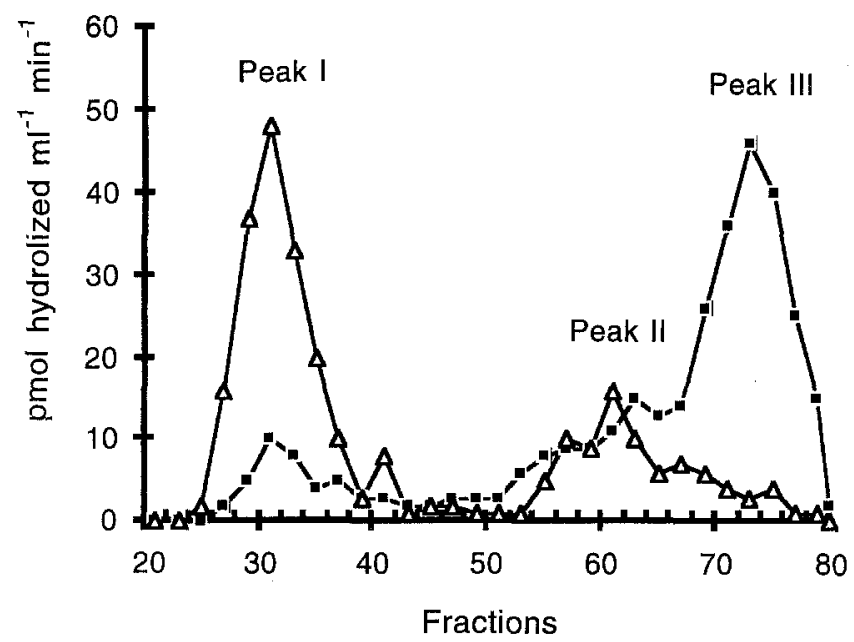

Fig. 1. Hydrolysis of cAMP and cGMP. Aliquots of the fractions from DEAE-Sephacel were measured to determine the hydrolytic activity in vitro. Samples were measured in duplicate and are representative of two different ureter preparations. Three peaks can be determined with different specificity for either cAMP (filled squares) or cGMP (open triangles)

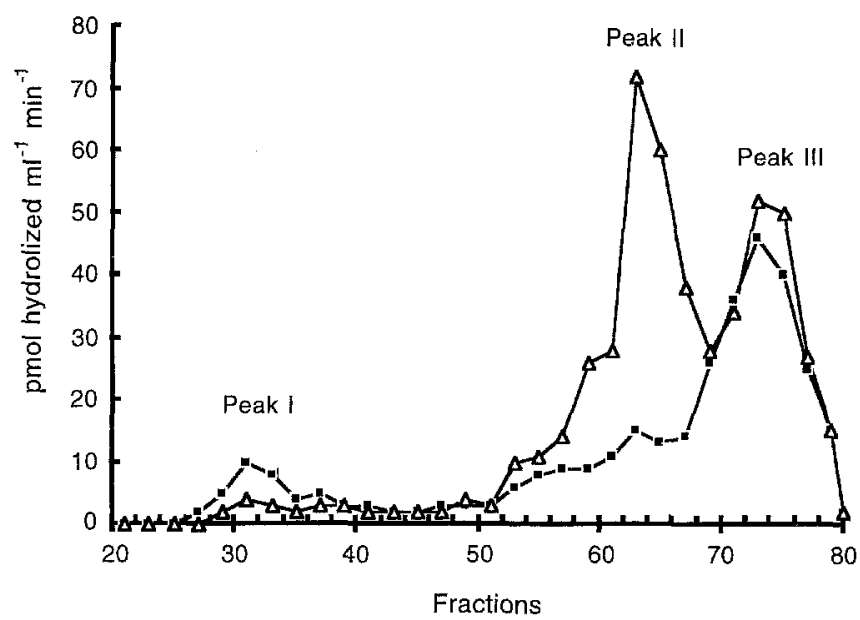

Fig. 2. Effect of cGMP on cAMP hydrolysis. cAMP hydrolysis was measured after the addition of $5 \mu M$ cGMP to the assay tubes. Samples were measured in duplicate and are representative of two different ureter preparations. Note the inhibitory effect of cGMP in peak I and its strong stimulatory effect in peak II. - CAMP; $-\triangle-\mathrm{cAMP}+\mathrm{cGMP}$

Peak I (fractions 27-35) which eluted at low ionic strenght, catalyzed the hydrolysis of cAMP and cGMP with a preference for cGMP as the substrate (ratio, 4.1:1). The addition of $40 \mathrm{nM}$ bovine-heart calmodulin and $10 \mu M \mathrm{CaCl}_{2}$ activated cAMP and cGMP hydrolysis by a factor of up to 1.5 (Fig. 3). These findings suggest the presence of calmodulin-sensitive PDE, or PDE I. Peak I exhibited a Michaelian kinetic behavior, with the $K_{\mathrm{m}}$ value for cGMP being $1.02 \mu M$ (Table 1). Although the hydrolysis of cAMP in peak I was low, a slight inhibition by $5 \mu M$ cGMP was noted, which suggests the presence of cGMP-inhibited PDE, or PDE III (Fig. 2). To determine the presence of PDE III in peak I, rechromatography using Q-Sepharose was performed, and PDE I (calmodulin-
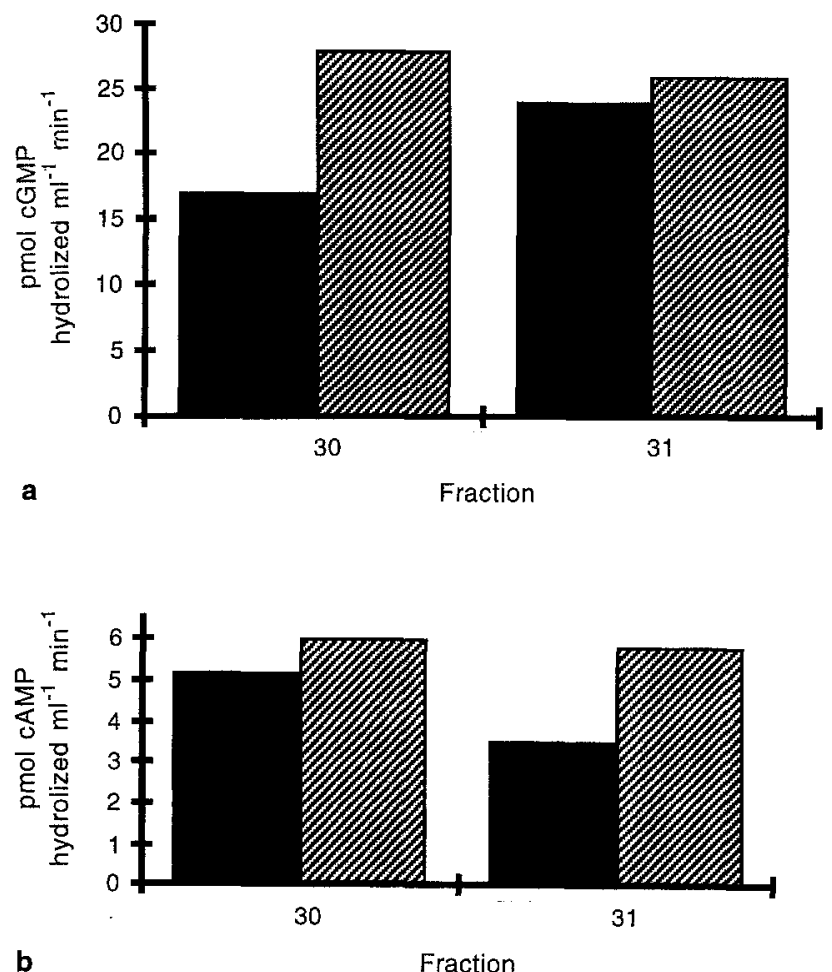

Fig.3. Effect of calcium and calmodulin on cGMP a (upper panel) and cAMP b (lower panel) hydrolysis. Calmodulin (40 $\mathrm{n} M$ ) and calcium chloride $(10 \mu M)$ were added to active fractions and the standard assay was performed. Fractions 30 and 31 showed an increase in hydrolytic activity; in all other fractions measured,

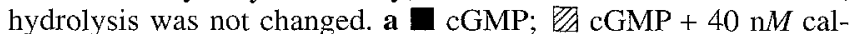
modulin. b 1 cAMP; $\mathbb{C}$ cAMP + $40 \mathrm{n} M$ calmodulin

Table 1. $K_{\mathrm{m}}$ values and reaction velocity of peaks I-III

\begin{tabular}{|c|c|c|}
\hline & $K_{\mathrm{m}}$ value & 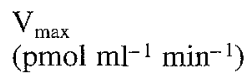 \\
\hline Peak I & $1.02 \mu M$ & 8.30 \\
\hline Peak II & $5.10 \mu M$ & 52.63 \\
\hline Peak III & $1.43 \mu M$ & 6.25 \\
\hline
\end{tabular}

From the dose-response curve generated for cAMP hydrolysis of the peak fractions after DEAE-Sephacel separation, $K_{\mathrm{m}}$ and $\mathrm{V}_{\max }$ values were evaluated. The substrate concentrations used ranged from 0.1 to $100 \mu M$. Data represent mean values for duplicate determinations obtained in two representative experiments using different ureter preparations

sensitive PDE) was detected in the only peak eluted from the column. The addition of cGMP did not alter the hydrolysis of cAMP (data not shown). Peak II (fractions 52-66) catalyzed the hydrolysis of cAMP and cGMP to a comparable degree. Since $5 \mu M$ cGMP stimulated cAMP hydrolysis by a factor of up to almost 7 (Fig. 2), peak II was designated as PDE II (cGMP-stimulated PDE). The $K_{\mathrm{m}}$ value for this peak was $5.10 \mu M$ (Table 1). Peak III (fractions 70-76) hydrolyzed only cAMP, with the $K_{\mathrm{m}}$ value being $1.43 \mu M$ (Table 1). This result suggests the presence of PDE IV (cAMP-specific PDE) in peak III.

The effect of different PDE inhibitors, namely, papaverine (nonselective PDE inhibitor), quazinone (selec- 
Table 2. Inhibitory effect of various PDE inhibitors on different peaks of PDE activity in human ureter preparations

\begin{tabular}{lcccc}
\hline PDE inhibitor & \multicolumn{3}{l}{$\mathrm{IC}_{50}(\mu M)$} & \\
\cline { 2 - 5 } & $\begin{array}{l}\text { Peak I } \\
\text { (cGMP) }\end{array}$ & $\begin{array}{l}\text { Peak I } \\
\text { (cAMP) }\end{array}$ & Peak II & Peak III \\
\hline Papaverine & 4.5 & 17 & 3 & 2 \\
Quazinone & 50 & 7 & 70 & $>100$ \\
Rolipram & $>100$ & 100 & $>100$ & 0.5 \\
Zaprinast & 0.35 & 2 & 25 & 50 \\
\hline
\end{tabular}

The inhibitory effect of various PDE inhibitors on different peaks of PDE activity in human ureter preparations was measured using $1.0 \mu M$ cAMP as a substrate. For peak I, $1.0 \mu M$ cGMP was also used. Data represent $\mathrm{IC}_{50}$ values for duplicate determinations obtained in two representative experiments using different ureter preparations as calculated using incremental concentrations of PDE inhibitors

tive PDE III inhibitor), rolipram (selective PDE IV inhibitor), and zaprinast (PDE V and I inhibitor) was tested. The fraction with the highest activity in each peak (fraction 31 for peak I, fraction 62 for peak II, and fraction 74 for peak III) was used. Table 2 summarizes the $\mathrm{IC}_{50}$ values determined from the concentration-response curves.

Papaverine was found to exert relatively potent inhibition, but it showed nonselective inhibitory effects on all forms of PDE. At a concentration of $10^{-4} \mathrm{M}$, it produced $100 \%$ inhibition of all PDE isoforms except PDE I with cAMP as the substrate. Zaprinast was the most potent inhibitor of peak $\mathrm{I}$, with $\mathrm{IC}_{50}$ values falling within the submicromolar range. This findings supports the presence of PDE $I$ in peak I. Quazinone also inhibited peak I dose_dependently, especially when cAMP served as the substrate. No selective inhibition was found for peak II. Only papaverine inhibited the PDE activity at relatively low concentrations $\left(\mathrm{IC}_{50}, 3 \mu M\right)$. All other inhibitors tested could not induce $50 \%$ inhibition even at the maximal concentrations tested $\left(10^{-4} M\right)$. This finding is in accordance with the presence of PDE II in this peak. Rolipram, the selective inhibitor of PDE IV, inhibited peak III selectively with the $\mathrm{IC}_{50}$ value being $0.5 \mu \mathrm{M}$. Quazinone and zaprinast inhibited peak III at $\mathrm{IC}_{50}$ values of $>100 \mu M$ and the $\mathrm{IC}_{50}$ value for papaverine was $2 \mu \mathrm{M}$. The presence of PDE IV in this peak is supported by these results.

\section{Organ bath study}

None of the ureteral muscle strips showed any spontaneous activity. The human ureteral strips were precontracted with $80 \mathrm{mM} \mathrm{KCl}$ and produced a maximal tonus contraction of $7.5 \pm 0.9 \mathrm{mN}(n=14)$. All PDE inhibitors tested induced a dose-dependent relaxation with different potency. At the highest concentration tested $\left(10^{-4} \mathrm{M}\right)$, papaverine and rolipram were capable of inducing total and maximal relaxation of the muscle strips with similar potency $(P<0.05)$. Quazinone and zaprinast relaxed the strips with lower potency $(P<0.05$; Table 3$)$. Papaverine started to relax the strips at a concentration of $10^{-5} \mathrm{M}$; this nonselective inhibitor produced $100 \%$ relaxation at a con-

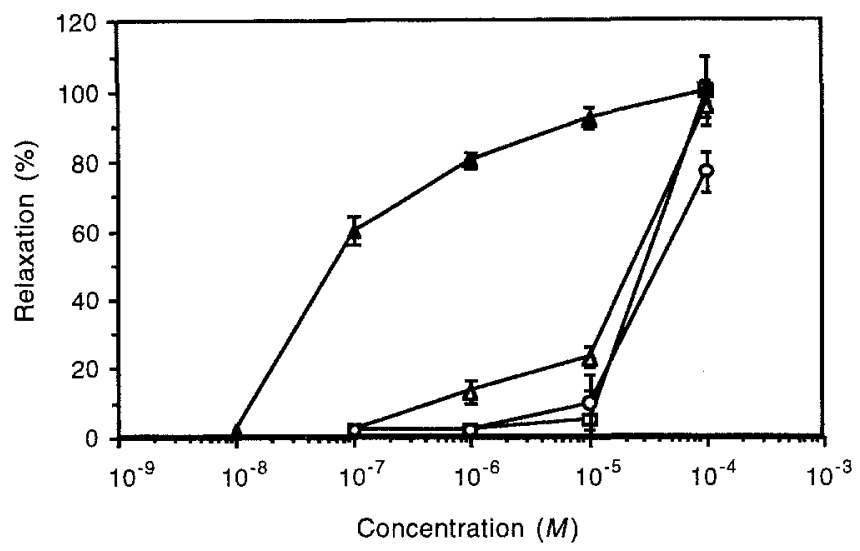

Fig.4. Relaxant effect of cumulatively increasing concentrations of the nonselective PDE inhibitor papaverine and the selective in hibitors quazinone, zaprinast, and rolipram on human ureteral strips precontracted with $80 \mathrm{~m} M \mathrm{KCl}$. Each data point represents the mean value \pm SEM for 3-7 ureteral strips. - $\square$ - Papaverine; $\triangle \triangle$ quazinone; $-\mathrm{O}-$ zapparinast; $\_$rolipram

Table 3. Relaxant effect of various PDE inhibitors on isolated human ureteral strips preconcentrated with $80 \mathrm{mM} \mathrm{KCl}$

\begin{tabular}{llcccc}
\hline $\begin{array}{l}\text { PDE } \\
\text { inhibitor }\end{array}$ & \multicolumn{2}{l}{$\begin{array}{l}\text { Relaxation (\%) } \\
\text { Inhibitor concentration }\end{array}$} & $\begin{array}{l}\mathrm{EC}_{50} \\
(\mu M)\end{array}$ \\
\cline { 2 - 5 } & $10^{-7} M$ & $10^{-6} M$ & $10^{-5} M$ & $10^{-4} M$ & \\
\hline Papaverine & 0 & 0 & 5.0 & 100 & 30 \\
Quazinone & 1.5 & 11.8 & 24.8 & 86.8 & 25 \\
Zaprinast & 0 & 0 & 8.1 & 75.5 & 40 \\
Rolipram & $56.8^{*}$ & $77.1^{*}$ & $89.7^{*}$ & 100 & 0.1
\end{tabular}

Data represent mean values for 3-7 ureteral strips. The $\mathrm{IC}_{50}$ value was determined graphically

$* P<0.05$ (between-group analysis)

centration of $10^{-4} \mathrm{M}$. The $\mathrm{EC}_{50}$ value was $30 \mu \mathrm{M}$. Quazinone showed a relaxant effect at an $\mathrm{IC}_{50}$ value of $25 \mu \mathrm{M}$. The maximal concentration $\left(10^{-4} \mathrm{M}\right)$ produced $86.8 \% \pm$ $5.4 \%$ relaxation. Zaprinast relaxed the human ureteral strips in this study at an $\mathrm{EC}_{50}$ value fo $40 \mu M$, and the maximal concentration used $\left(10^{-4} M\right)$ induced $75.5 \% \pm$ $12.9 \%$ relaxation. Rolipram concentration of $10^{-7} \mathrm{M}$ relaxed the preparations by $56.8 \% \pm 5.5 \%$, and a concentration of $10^{-4} M$ produced $100 \%$ relaxation (Fig. 4 ). The relaxant potency $\left(\mathrm{EC}_{50}\right)$ of all the inhibitors tested is listed in Table 3.

\section{Discussion}

Our results demonstrate the presence of at least three cyclic nucleotide PDE isoenzymes in the human ureter. In our study, the supernatant was used as the source of PDE representing the cytosolic fraction. However, we are aware that the particulate fraction of smooth-muscle cells has funcitonal significance, although we found only $18 \%$ activity there. Weiss and Wheeler [12] prepared cytosolic fractions from guinea-pig ureters by centrifuging the homogenate at $50,000 \mathrm{~g}$; centrifugation of the super- 
natant at $100,000 \mathrm{~g}$ has failed to sediment additional activity.

The presence of PDE I in peak I was shown in our study, where calmodulin stimulated the activity of this PDE isoenzyme by a factor of almost 2 . Zaprinast selectively inhibited hydrolysis at low concentrations $\left(\mathrm{IC}_{50}\right.$, $0.35-2 \mu M$ ). As expected, kinetics studies performed in this peak revealed a PDE with high affinity for cGMP $\left(K_{\mathrm{m}}, 1.02 \mu M\right)$. For most PDE I preparations from mammalian tissues, the calmodulin-stimulated activity is 6-20 times greater than the basal activity. In the present study the activity of PDE I was stimulated by a factor of only 2 by calmodulin, but stimulation was reproducible in different tissue extracts. A similar result has also been obtained in the dog ureter [13]. The reason for this wide variation in enzyme stimulation by calmodulin is not known, but a number of factors may contribute to this variation [14]. Moreover, the extent of calmodulin stimulation is also dependent on the assay conditions. In our study, nonsaturating substrate concentrations were used. In this series, the presence of PDE I in peak I was further supported by the selective inhibition of this peak by zaprinast, whereas the other selective PDE inhibitors tested inhibited the activity only at very high concentrations, with the $\mathrm{IC}_{50}$ values being $>50 \mu M$.

A second peak hydrolyzed cAMP and cGMP to a comparable degree. The addition of cGMP stimulated cAMP hydrolysis by several orders of magnitude; this suggests the presence of PDE II (cGMP-stimulated PDE) in peak II. The most potent inhibitor for this peak was papaverine (a nonselective PDE inhibitor; $\mathrm{IC}_{50}, 2 \mu M$ ). The selective PDE inhibitors tested did not significantly inhibit cAMP hydrolysis except at very high concentrations $\left(\mathrm{IC}_{50}, 25\right.$ $100 \mu M)$. Since no selective inhibitor of PDE II has thus far been identified, the above findings support the presence of PDE II in peak II. Our studies on the hydrolytic properties of peak II showed that this peak contains a lowaffinity $\left(K_{\mathrm{m}}, 5.10 \mu M\right)$ PDE. The main characteristic of PDE II is that cAMP hydrolysis is markedly stimulated by micromolar concentrations of cGMP. The mechanism of this activation is believed to result from the association of cGMP with an allosteric binding site on the enzyme, leading to a conformational change at a separate hydrolytic binding site [15].

The third peak of activity (peak III) selectively hydrolzyed cAMP. It was not stimulated by calmodulin and was therefore designated as PDE IV, or cAMP-specific PDE. The $K_{\mathrm{m}}$ value $(1.43 \mu M)$ was also in accordance with the results of other studies on PDE IV [16]. Further support for this conclusion was its sensitivity to inhibition by rolipram $\left(\mathrm{IC}_{50}, 0.5 \mu M\right)$, which is categorized as a PDE IV-selective inhibitor, and its complete insensitivity to cGMP and to the PDE III-selective inhibitor quazinone $\left(\mathrm{IC}_{50},>100 \mu M\right)$.

Therefore, our results show the presence of three PDE isoenzymes in the human ureter. Since many factors influence the functional significance of an enyzme, in vitro studies were done to determine the PDE isoenzyme whose inhibition by a specific PDE inhibitor would lead to the strongest ureteral relaxation at the lowest concentration. No spontaneous contraction was found in our ureter preparations. This absence of spontaneous contractions is consistent with the findings of other researchers. However, spontaneous and regular contractions of ureteral strips have also been reported. It may be hypothesized that anoxia may have provoked spontaneous ureteral activity in some cases, as it occurred more often in abnormal or damaged ureters [4].

Papaverine relaxed the strip preparations at an $\mathrm{EC}_{50}$ value of $20 \mu \mathrm{M}$. It must be noted that this nonselective PDE inhibitor produced only $5 \%$ relaxation at concentrations of $10^{-5} M$, whereas $100 \%$ relaxation was reached at concentrations of $10^{-4} M($ Fig. 4). This type of "slope" may have therapeutic significance, since an excessive or inadequate effect may occur if the dose of the drug is not carefully adjusted [5]. Although the relaxant effect of papaverine on the isolated human ureter was first shown long ago [6], there are conflicting reports regarding its effectiveness for the relief of ureteral colic [7]. Our findings suggest a narrow therapeutic range for papaverine regarding ureteral relaxation, with relatively high doses being needed to produce a significant degree of relaxation. This underscores the limited use of papaverine in the treatment of ureteral colic.

Zaprinast relaxed the ureteral strips in a dose-dependent manner but with low potency $\left(\mathrm{EC}_{50}, 40 \mu M\right)$, despite the observation that it inhibited PDE activity in the ureter homogenates at a low concentration $\left(\mathrm{IC}_{50}, 0.35-2 \mu M\right)$. Quazinone also showed a weak relaxing effect on the human ureteral smooth muscle only at high concentrations. This findings confirms the lack of PDE III in the ureteral homogenates.

Rolipram (PDE IV inhibitor) was the most potent drug in relaxing ureteral strips $\left(\mathrm{EC}_{50}, 0.1 \mu \mathrm{M}\right)$. At the lowest concentration tested $\left(10^{-7} M\right)$, relaxation of $56.8 \%$ was achieved. As shown in Fig. 4, rolipram effectively inhibited PDE IV activity at low concentrations $\left(\mathrm{IC}_{50}, 0.1 \mu M\right)$. This close correlation between the functional response (relaxation) of the tissue and the biochemical response (PDE IV activity inhibition), suggests that PDE IV isoenzymes are physiologically important in the regulation of ureteral smooth-muscle tone. In contrast to rolipram, the other selective inhibitors tested showed no such correlation.

Our experiments were performed using isolated ureteral preparations in which basal turnover rates of cyclic nucleotides are low; therefore, relatively high concentrations of PDE inhibitors are needed to elevate cyclic nucleotide levels enough to produce a change in tissue tone. In contrast to this in vitro situation, cyclic nucleotide turnover rates are more elevated in vivo, with PDE inhibitors consequently having a much greater effect on tissue levels of cyclic nucleotides [9].

Specifically, there are three effects of PDE IV inhibitors that should be useful in the treatment of ureteral colics. First, relaxation of the ureter at the site of the impacted stone should relieve the colic pain and facilitate stone passage. Second, the edema and inflammation that usually accompany ureteral stones are eased by PDE IV inhibitors. Finally, rolipram induces minimal cardiovascular effects when given at the required doses, enabling the systemic application of this drug for this purpose. A num- 
ber of substances different from rolipram are classified as PDE IV inhibitors and have been clinically investigated. These drugs have been used in the treatment of asthma bronchiale, inflammation, and depression. It remains to be determined as to whether these agents act on the human ureter in a manner comparable with that of rolipram. We think that our study may open a new approach for the treatment of ureteral colic. Despite the likelihood that there are species differences in the PDE-isoenzyme pattern of the ureter, animal studies should be done to examine a possible ureter-selective effect of rolipram in vivo.

\section{References}

1. Drach GW (1986) Urinary lithiasis. In: Walsh PC, Gittes RF, Perlmutter AD, Stamey TA (eds) Campbell's urology. WB Saunders, Philadelphia, pp 1094-1122

2. Hartmann M (1991) Urologische Notfall-Situationen (ohne Verletzungen). In: Altwein JE, Rübben H (eds) Urologie. Ferdinand Enke, Stuttgart, 395-424

3. Gruber CM (1928) The effect of morphine and papaverine upon the peristaltic and antiperistaltic contractions of the ureter. J Pharmacol Exp Ther 33:191-199

4. El-Sherif AE, Foda R, Norlen LJ, Yahia H (1990) Treatment of renal colic by prostaglandin synthetase inhibitors and avafortan (analgesic antispasmodic). Br J Urol 66:602-605

5. Friedman MR (1990) Nonsteroidal anti-inflammatory drugs facilitate stone passage. Urology $35: 374$

6. Caine M (1984) The autonomic pharmacology of the urinary tract. In: Caine $M$ (ed) The pharmacology of the urinary tract. Springer, Berlin Heidelberg New York, pp 5-27

7. Itoh T (1991) Pharmacomechanical coupling in vascular smooth muscle cells, an overview. Jpn J Pharmacol 55:1-9

8. Beavo JA (1990) Multiple phosphodiesterase isoenzymes. Background, nomenclature and implications. In: Beavo JA,
Houslay MD (eds) Cyclic nucleotide phosphodiesterases: structure, regulation and drug action. John Wiley \& Sons, West Sussex, pp 3-15

9. Thompson WJ, Brooker G, Appleman MM (1971) Assay of cyclic nucleotide phosphodiesterases with radioactive substrates. Biochemistry 10:311

10. Lakey T, Pyne N, Murphy G (1990) Cyclic nucleotide. In: Siddle K, Hutton JC (eds) Peptide hormone action. A practical approach. IRL/Oxford University Press, New York, pp 101-108

11. Dixon M, Webb EC (1979) Enzyme kinetics. In: Dixon M, Webb EC (eds) Longmans, London, pp 47-206

12. Weiss RM, Wheeler MA (1988) Insulin activation of cyclic AMP phosphdiesterase in intact Ureteral segments. J Pharmacol Exp Ther 247:630-634

13. Weiss RM (1981) Resistance of a separate from of canine ureteral phosphodiesterase activity to inhibition by xanthines and papaverine. Biochem Pharmacol 30:2371-2374

14. Wang JH, Sharma RK, Mooibroek MJ (1990) Calmodulin stimulated cyclic nucleotide phosphodiesterase. In: Beavo JA, Houslay MD (eds) Cyclic nucleotide phosphodiesterases: structure, regulation and drug action. John Wiley \& Sons, West Sussex, pp 19-46

15. Reeves ML, England PJ (1990) Cardiac phosphodiesterases and the functional effects of selective inhibition. In: Beavo JA, Houslay MD (eds) Cyclic nucleotide phosphodiesterases: structure, regulation and drug action. John Wiley \& Sons, West Sussex, pp 229-312

16. Conty M, Swinnen JV (1990) Structure and function of the rolipram sensitive, low $\mathrm{K}_{\mathrm{m}}$ cyclic cAMP phosphodiesterase: a family of highly related enzymes. In: Beavo JA, Houslay MD (eds) Cyclic nucleotide phosphodiesterases: structure, regulation and drug action. John Wiley \& Sons, West Sussex, pp 68-91

17. Beavo JA, Raifsnyder DH (1990) Primary sequence of cyclic nucleotide phosphodiesterase isozymes and the design of selective inhibitors. TIPS 11:150-155 